\title{
Cristianismo bajo Septimio Severo y Caracalla ${ }^{1}$
}

\author{
Paloma aguado Garcia *
}

\section{RESUMEN ABSTRACT}

Contrariamente a lo afirmado por la tradición cristiana, a Septimio Severo

y a Caracalla no podemos considerarles perseguidores de los cristianos. Durante sus reinados se produjeron persecuciones locales, al negarse los cristianos a participar en celebraciones religiosas relacionadas con el culto imperial. Dichas persecuciones tienen un caracter exclusivamente local, $y$ son fruto de la actuación puntual de las administraciones provinciales, sin estar refrendadas por un edicto imperial. La actitud de los emperadores hacia las comunidades cristianas asentadas en el Imperio fue tolerante y abierta, incluso los propios cristianos evitaban enfrentamientos directos con la autoridad imperial con motivo de las celebraciones públicas. Tampoco la Constitución Antoniniana tuvo repercusiones negativas hacia
Septimio Severo and Caracalla can not be considered persecutors of the christians in opposition to the idea stablished by the Christian tradition. With the refusal of Christians to take part in religious celebrations related to imperial cult. Several persecutions took place during the different periods of these two Emperors's Kingdoms. These pursuits have an exclusive local character and they are isolated results of the administrations of the provinces, without being approved by the imperial edict. The Emperor's attitude towards the Christians comunities settled down in the Empire was open-minded and full of tolerance. The Christians themselves avoided direct confrontations with the imperial authority when the public celebrations were being held. There can not be found any negative consequences in the Constitutio

* Doctora en Historia Antigua. 
los cristianos, que se vieron afectados por el edicto del 212 de igual manera que cualquier otra comunidad religiosa.
Antoniniana relating to the Christians Community which was affected by the edict dated in 212 in the same way as any other religious community.

El cristianismo merece consideración aparte dentro de las religiones orientales, por encontrarse reducida a un ámbito territorial menor, por tener menores cauces de difusión y básicamente, por su monoteísmo radical, que contrasta en el marco general de las religiones del Imperio ${ }^{2}$.

La tradición cristiana se complace en presentar a Septimio Severo como un perseguidor de los cristianos ${ }^{3}$, basándose en la información de una única fuente pagana, la Historia Augusta. En ella se narra que en su viaje por Palestina en el 202, promulgó leyes en contra de los judios y cristianos, prohibiendo a estos últimos hacer conversos y prescribe muertes y penas por desobediencia:

"In itinere Palaestinis plurima iura fundavit. ludaeos fieri sub gravi poena vetuit. Idem etiam de Christianis sanxit" (H.A., Vita Sev. 17, 1) ${ }^{4}$.

Esta noticia siempre ha planteado problemas referentes a la actitud tolerante de Severo frente a los cristianos. Para Marta Sordi ${ }^{5}$, la información

\footnotetext{
Quiero agradecer al profesor Santiago Montero, la lectura y las sugerencias aportadas al presente trabajo, asi como a Dña Pilar Fernandez Uriel su amabilidad y disposición.

2 Para mayor información sobre el cristianismo en época severa ver: H. GREGOIRE, Les persécutions dans l'empire romain, Bruxelles, 1964. págs. 24-41; P. KEREszTES, "The Emperor Septimius Severus: A Precursor of Decius", Historia 19, 1970, págs. 565-578; P. KERESzTES, "The Imperial Roman Government and the Christian Church I. From Nero to the Severi", en A.N.R.W. II, 23.1 (1979), págs. 247-315; J. HeLGELAND, "Christians and the Roman Army from Marcus Aurelius to Constantine", en A.N.R.W II, 23.1, 1979, págs. 724-834; M. SoRDI, "I rapporti fra il Cristianesimo e I'Impero dai Severi a Gallieno", en A.N.R.W. II, 23.1,(1979), págs. 340-374.; D. L. JoNES, "Christianity and The Roman Imperial Cult" en A.N.R.W. II, 23.2 (1980), págs. 1023-1053; M. Sordi, Los cristianos y el Imperio Romano, Madrid, 1988; E. Dal Cordo, I Severi e il Cristianesimo, Roma, 1990; N. Santos Yanguas, El cristianismo en el marco de la Crisis del siglo Ill en el Imperio Romano, Oviedo, 1996.

3 La tradición cristiana está representada en primer lugar por Eusebio (H.E, VI, 1 ss), que habla de una persecución de Severo contra las Iglesias y describe sus efectos en Egipto durante la prefectura de Q. Mecio Leto (201/202) y de su sucesor Subaziano Aquila (206-210). Después Sulpicio Severo (Chron. II, 32, 1-2), Orosio (VII, 17, 4-5) y San Jerónimo (Chron. Hieron. pág. 212) también hablan de la persecución.

"Durante su viaje dio muchas leyes a los Palestinos. Prohibió bajo severas penas hacerse judio. Respecto al cristianismo estableció una prohibición semejante" (H.A., Vita Sev. 17,1).

5 M. SoRDI, Los cristianos y el Imperio Romano, Madrid, 1988, pág. 82 ss.
} 
contenida en la Historia Augusta es falsa. En primer lugar basa su afirmación en que se consideraría una anacronismo histórico situar al mismo nivel, cristianismo y judaísmo, mientras que el primero aún se consideraba una superstitio illicita, el judaísmo estaba perfectamente asentado y constituido (religio licita) dentro del Imperio Romano desde el siglo I a.C. En segundo lugar, Septimio Severo concedió dispensas sobre las prácticas religiosas paganas a los judíos que desempeñaron cargos públicos ${ }^{6}$, y realizó construcciones monumentales en la zona de Galilea, con ayuda de las comunidades judías.

Durante los dos años siguientes, 203 y 204, los cristianos fueron perseguidos. Las actas de Perpetua y Felicidad, escritas probablemente por Tertuliano en el 203, describe la inocencia y el sufrimiento de las victimas de Cartago, al negarse a hacer el sacrificio por la salud del emperador. Esta persecución se ha considerado actualmente como se consideró en su tiempo, tanto por Tertuliano como por Hipólito, de carácter exclusivamente local, y no habría implicado de modo alguno la existencia de un edicto imperial, en el que el propio Septimio Severo se implicara en estas matanzas.

Los vota decennalia del año 202 que coincidieron con el regreso a Roma de Septimio Severo, la boda de Caracalla, con el natalis de Geta, y con la III liberalitas ${ }^{7}$, pudieron servir para intensificar el celo religioso, dada la abstención de las comunidades cristianas en estas celebraciones paganas, particularmente en África, donde por una especie de «patriotismo local», se practicó el culto imperial con mayor dedicación. Los cristianos incurrirían tanto en delito político como religioso y debido a las acusaciones de la multitud se les declaró hostes publici. Los magistrados establecerían una campaña de hostigamiento hacia estas comunidades, con el fin de acallar las protestas populares y hacerse más gratos a los ojos del emperador.

Sobre este tiempo, Hipólito de Roma en su Comentario a Daniel, afirma que los cristianos estaban siendo llamados a ser adoradores de los dioses, o a sufrir pena de muerte. Pero para este apologeta, rigorista y contrario a un compromiso personal en sus escritos con el Estado romano, Septimio Severo no era el responsable de la persecución, sino que la iniciativa recaería en los gobernadores provinciales, los magistrados, y también en las multitudes, tanto judías como paganas, que se

Digesto XXVII, 1, 15, 6. y L, 2, 3 ,

M. SORDI, Los cristianos..., págs. 83 ss. 
dedicaban a espiar a los cristianos y acusarlos de ser enemigos del Estado ${ }^{8}$.

Tertuliano nos cuenta que Severo requería a cristianos sanadores en su palacio; el asistente de su hijo Caracalla, siendo niño era cristiano ${ }^{9}$, y el propio emperador rescató altos cargos de la jerarquía cristiana de la violencia popular ${ }^{10}$.

"Sed et clarissimas feminas et clarissimos viros Severus sciens huius sectae esse non modo non laesit, verum et testimonio exornavit et populo furenti in nos palam restitit" (Tertuliano, Ad Scapulam IV, 6).

En su obra Ad Scapulam y Ad Nationes, menciona los ataques realizados contra los cristianos ${ }^{11}$, las insurrecciones populares en su contra, con el objetivo de obtener intervenciones más enérgicas de los magistrados contra ellos ${ }^{12}$, y comenta la abierta resistencia que el mismo Septimio Severo opuso a una de estas sublevaciones populares ${ }^{13}$, afirmando Tertuliano, que los cristianos son "los más fieles súbditos del emperador" y acusa a los magistrados como responsables tanto de los juicios como de las condenas a la comunidad cristiana.

A la luz de lo anteriormente indicado, podemos negar que existiese una persecución general bajo el reinado de Septimio Severo, y que la actitud de éste hacia ellos fue bastante tolerante. Las fuentes contemporáneas paganas como Dión Casio o Herodiano, y cristianas, como Hipólito, Clemente de Alejandría y Tertuliano, no informan sobre esta presunta persecución general. Tertuliano e Hipólito confirman la existencia de persecuciones locales muy puntuales al principio de su reinado, pero no las atribuyen a un edicto imperial, sino al odio popular, o al celo de algún gobernador provincial, y mantienen al margen de las mismas los propósitos del emperador, al que como ya se ha comentado, le atribuyen una actitud no hostil hacia los cristianos.

En los años sucesivos, los propios cristianos debieron de darse cuenta del error que para su seguridad representaba no participar en las celebraciones públicas tras los sucesos del 202 y 203, y adoptan una

Comentario a Danie/l, 15-20.

Ad Scap. 4,5.

10 Tertuliano, Ad Scap. IV, 5-6: "No solamente, no persiguió a ninguna persona notable cristiana, sino que las honró con su estima y las defendió contra el odio del pueblo".

Ad Nat. VII, 19.

Ad Scap. III, 1

Ad Scap. IV, 6. 
actitud más tolerante y complaciente en lo que respecta a la participación en manifestaciones y fiestas populares que no se oponían abiertamente con sus principios. No se negaban a rogar por la salud del emperador, pero no al conjunto de los dioses sino a su Dios único. Así Tertuliano nos cuenta que fueron las comunidades cristianas las primeras en adornar sus casas con guirnaldas, lucernas y ramos de laurel, con motivo de la gaudia publica del 211 ó 212, bajo Caracalla ${ }^{14}$. Eran los propios cristianos, quienes evitaban enfrentamientos con la autoridad imperial, convencidos de que se podría lograr un clima de tolerancia y convivencia entre la comunidad cristiana y la pagana, dicho periodo de estabilidad y paz era propiciado por la propia actitud del emperador Caracalla. Tertuliano, en su obra De Corona, que escribió en el 211, narra como los cristianos de la comunidad de Cartago, desaprobaron la actitud del soldado cristiano de la legio III Augusta, que se había negado a ponerse la corona por un exceso de escrúpulos y había infringido la disciplina militar, poniendo en peligro las buenas relaciones entre cristianos y autoridades imperiales (De Corona 1, 4-5).

Prácticamente la tolerancia de hecho que existía en este momento en el Imperio, instaurada desde Marco Aurelio, pasaba por la circunstancia de que los cristianos aceptaran las reglas de convivencia política, y que participaran de las celebraciones paganas sin rechazos ni perjuicios.

Durante el reinado de Caracalla, sabemos por Tertuliano, que afirma en el $\mathrm{Ad}$ Scapulam, dirigido al proconsul $P$. Julio Tertulo, que gobernó Africa, entre el 211 y el 213 , que se produjeron persecuciones locales en esta zona, realizadas por el comandante de la legión III Augusta, y por el gobernador de Mauritania ${ }^{15}$, pero de nuevo son episodios puntuales, no atribuibles ni a la actitud ni al interés del Emperador por castigar a estas comunidades. Esta persecución de caracter local no supuso perjuicio para los cristianos en el Imperio. De hecho, algunos cristianos gozaban de gran reputación en el Imperio; por ejemplo, Orígenes tiene un prestigio tan grande, que el gobernador de Arabia en el año 215, reinando Caracalla, solicita permiso al obispo de Alejandría y al prefecto de Egipto, para que Orígenes acuda a Arabia para dar unas conferencias ${ }^{16}$. Fruto de estas buenas relaciones se puede considerar el Diálogo sobre el destino y el libre arbitrio, que el cristiano Bardesano dedicó a Caracalla o a Heliogábalo.

14 De ldol. XV, 1ss.

15. Ad Scap. IV, 8.

16 M. Sondi, Los cristianos y el Imperio Romano, Madrid, 1988, pág. 156 
Tampoco la Constitutio Antoniniana tuvo repercusiones negativas para los cristianos ${ }^{17}$. De hecho no se exceptúa a los cristianos de los beneficios obtenidos con el edicto.

El emperador Caracalla se había distinguido por una política religiosa tolerante y abierta que caminaba progresivamente hacia el sincretismo, en este contexto tendrían cabida todos los cultos existentes, desde los más tradicionales romanos, hasta los orientales y por supuesto, tanto el cristianismo como el judaísmo.

En definitiva, podemos afirmar que con Caracalla se disfruta de un período de tranquilidad religiosa en el Imperio. Ninguna fuente, aparte de Tertuliano habla de persecuciones durante el reinado del emperador Caracalla, ni en África, ni en otra parte del imperio, y la que nombra este es de carácter exclusivamente local y muy puntual, sin repercusiones notables para las comunidades cristianas alli asentadas. Entre las fuentes paganas, tan solo Dión Casio ${ }^{18}$, habla de una represión a los Osroenos, donde el cristianismo estaba muy arraigado y el rey Abgar XI, era cristiano, pero no hay elementos para considerarlo como una intervención de finalidad religiosa y menos anticristiana.

17 Algunos historiadores así lo defendían como E. PERrot, "Sur l'Edit de Caracalla de 212. et les persécutions contre les chrétiens", Revue histoire de Droit Francais et Etranger, IV, 1924, págs. 367 ss. Hoy esta idea ha sido ampliamente refutada por la mayoría de los investigadores contemporáneos, considerando que las comunidades cristianas se ven igualmente afectadas por el edicto que el resto de las confesiones religiosas. El artículo más concluyente sobre el tema es el de P. KenESzTES, "The Constitutio Antoniniana and the Persecution under Caracalla", A.J.Ph. 91, 1970. págs. $446-459$.

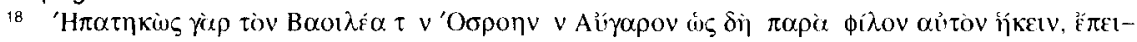
$\tau \alpha \sigma v \lambda \lambda \alpha \beta\langle i, v \dddot{\varepsilon} \delta v \sigma \varepsilon$ (Dion Casio, 77 12, 1-2). 